\title{
DOSES E ÉPOCAS DE APLICAÇÃO DE MANGANÊS VIA FOLIAR NO CULTIVO DE SOJA CONVENCIONAL E EM DERIVADA TRANSGÊNICA RR
}

\author{
RATES AND STAGES OF FOLIAR MN APPLICATION IN THE CONVENTIONAL \\ SOYBEAN CROP AND ITS GENETICALLY MODIFIED RR DESCENDANTS
}

\author{
Everson Reis CARVALHO ${ }^{1}$; João Almir OLIVEIRA ${ }^{2}$; Jaime COSTA NETO ${ }^{3}$; \\ Cibele Aparecida Teixeira da SILVA ${ }^{4}$; Valquíria de Fátima FERREIRA ${ }^{5}$ \\ 1. Engenheiro Agrônomo, DSc., Professor substituto, Setor de Sementes, Departamento de Agricultura (DAG), Universidade Federal de \\ Lavras (UFLA), Lavras, MG, Brasil, eversonreiscarvalho@ hotmail.com; 2. Professor, DSc., Setor de Sementes, DAG, UFLA, Lavras, \\ MG; 3. Engenheiro Agrônomo, MSc., Syngenta Seeds Ltda, Uberlândia, MG; 4. Engenheira Agrônoma, MSc., Doutoranda, \\ USP/ESALQ, Piracicaba, SP; 5. Engenheira Agrônoma, MSc., Doutoranda em Fitotecnia, DAG/UFLA, Lavras, MG.
}

RESUMO: O objetivo com este trabalho foi avaliar o efeito da aplicação foliar de manganês sobre as características agronômicas de cultivares de soja convencionais e em suas derivadas transgênicas RR (Roundup Ready®, evento GTS 40-3-2). O ensaio foi conduzido na Universidade Federal de Lavras (UFLA), Lavras, MG, em blocos casualizados, com três repetições e esquema fatorial 4 × 4 × 2, sendo quatro cultivares de soja, duas convencionais e suas derivadas RR (BRS Celeste e BRS Baliza RR; BRSGO Jataí e BRS Silvânia RR), quatro doses de Mn via foliar (0; 200; 400 e $\left.600 \mathrm{~g} \mathrm{Mn} \mathrm{ha}^{-1}\right)$ e dois estádios de aplicação $\left(\mathrm{R}_{1}\right.$ ou $\left.\mathrm{R}_{3}\right)$. Foram avaliadas as características agronômicas: índice de acamamento; número de legumes por planta; peso de mil sementes e produtividade de sementes. A transgenia RR em soja não proporciona maior resposta à aplicação de $\mathrm{Mn}$, sendo esta possivelmente condicionada ao genótipo. Há aumento na produtividade de sementes de soja das cultivares Celeste e Baliza RR em função da aplicação foliar de Mn, em solo com teor de Mn abaixo do nível crítico e produtividades máximas obtidas com $150 \mathrm{~g} \mathrm{Mn} \mathrm{ha}^{-1}$. A aplicação foliar de Mn realizada em $R_{1}$ resulta em maior produtividade de sementes em relação à $R_{3}$.

PALAVRAS-CHAVE: Glycine max. Nutrição mineral. Soja Roundup Ready.

\section{INTRODUÇÃO}

O cultivo da soja transgênica RR (Roundup Ready®, Evento GTS 40-3-2) vem crescendo a cada ano e a sua relação com o Mn é ainda questionada. Huber et al. (2004) relataram que genótipos de soja RR foram menos eficientes na absorção de Mn e também apresentaram menor concentração do micronutriente no tecido foliar em comparação às convencionais.

Existem algumas explicações teóricas que podem sustentar estas alegações, que geralmente estão na direção de dois mecanismos gerais: (i) interação direta ou indireta entre glifosato e Mn, ou, (ii) diminuição na absorção e translocação de $\mathrm{Mn}$ resultante da alteração genética (LOECKER et al., 2010).

Em relação à interação direta ou indireta entre glifosato e Mn, Bott et al. (2008) verificaram que a aplicação de glifosato pode exercer efeito negativo no crescimento da planta e no estado nutricional, sugerindo uma interrelação com fatores ambientais. Zobiole et al. (2010) concluíram que o estado nutricional da soja RR é afetado pelo glifosato e que as recomendações nutricionais para os cultivos RR devem considerar a eficiência nutricional reduzida imposta pela transgenia RR, bem como o impacto adicional do glifosato. Entretanto, Correia e Durigan (2009) constataram que o glifosato não prejudicou a absorção ou o metabolismo do Mn. Isto corrobora com Rosolem et al. (2010), que em condições controladas, não encontraram evidências de efeitos negativos do glifosato na absorção, acúmulo e distribuição do Mn na soja $R R$ e que a transgenia RR não levou a mudanças significativas na resposta da planta a este elemento. Para Stefanello et al. (2011) a aplicação de glifosato na soja transgênica RR não apresentou efeito nos teores foliares de nutrientes. Em trabalho similar, Basso et al. (2011) concluíram que a aplicação de glifosato na cultura da soja RR não afeta a absorção e os teores foliares de $\mathrm{Mn}$ e que em solos com teores de $\mathrm{Mn}$ acima do suficiente a aplicação do herbicida glifosato não requer a suplementação foliar de Mn em soja RR.

Quanto à redução na absorção e translocação de Mn resultante da alteração genética RR, Gordon (2007) avaliando adubações com Mn em soja RR e convencional, verificou que a cultivar convencional KS 4202 apresentou produção superior que sua isolinha resistente ao glifosato, KS 4202 RR, na ausência de Mn. Nesta condição, observou-se que o teor foliar de Mn na soja RR era menor que o observado na convencional. Com 
adições crescentes de $\mathrm{Mn}$, a soja RR respondeu favoravelmente à aplicação, sugerindo que este material genético, não acumula $\mathrm{Mn}$ da mesma maneira que a convencional. Loecker et al. (2010) trabalhando com dois pares de cultivares, convencional e sua derivada transgênica $\mathrm{RR}$, e Mn aplicado via solo e foliar $\left(\mathrm{R}_{1}\right)$, observaram que a resposta da soja à aplicação de Mn foi influenciada pelo genótipo e que a resistência ao glifosato (RR) não resultou conclusivamente em deficiência de Mn ou maior resposta à aplicação. Relataram também que nem todos os pares de isolinhas (convencional e RR) vão responder da mesma forma, indicando a necessidade de trabalhos adicionais para confirmar esta observação. Andrade e Rosolem (2011) verificaram que o glifosato não ocasiona efeito depressivo na absorção e no transporte de Mn na planta de soja RR, e que a inclusão do gene de resistência ao glifosato não afeta a nutrição com $\mathrm{Mn}$ na cultivar Valiosa RR, bem como não interfere na produção de matéria seca da planta.

Pelos resultados divergentes observa-se, de forma geral, que embora a resposta da soja ao $\mathrm{Mn}$ possa ser influenciada pelo genótipo, nem a absorção de Mn, tão pouco a capacidade de resposta ao micronutriente foi conclusivamente afetada pela tolerância ao glifosato em soja RR, o que indica a necessidade de trabalhos complementares. Assim, o objetivo neste trabalho foi avaliar o efeito da aplicação foliar de manganês sobre as características agronômicas de cultivares de soja convencionais e em suas derivadas transgênicas RR.

\section{MATERIAL E MÉTODOS}

O experimento foi conduzido no campo experimental do Departamento de Agricultura, da Universidade Federal de Lavras (UFLA), em Lavras, MG, latitude $21^{\circ} 14^{\prime} \mathrm{S}$, longitude $45^{\circ} 00^{\prime} \mathrm{W}$ Gr. e $918 \mathrm{~m}$ de altitude. O clima, pela classificação climática de Köppen, é Cwa, temperado chuvoso (mesotérmico), com inverno seco e verão chuvoso, subtropical. A precipitação anual normal é de $1.529,7 \mathrm{~mm}$, sendo os maiores valores observados nos meses de dezembro (296 mm), janeiro (272 mm) e fevereiro (192 mm) (BRASIL, 1992; DANTAS et al., 2007). A precipitação pluviométrica $(\mathrm{mm})$ e temperatura média $\left({ }^{\circ} \mathrm{C}\right)$, diárias, no período da condução do experimento, estão representadas na Figura 1.

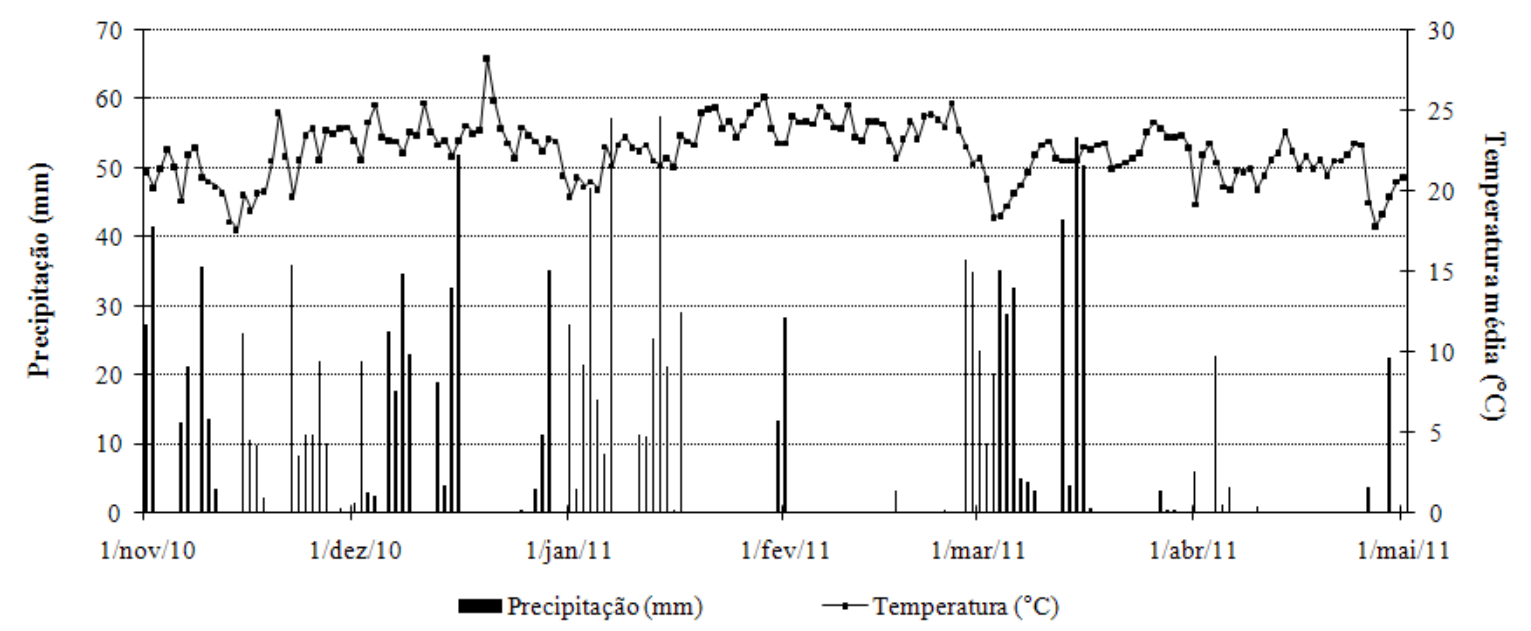

Figura 1. Precipitação pluviométrica $(\mathrm{mm})$ e temperatura média $\left({ }^{\circ} \mathrm{C}\right)$, diárias, verificadas durante a condução do experimento, entre novembro de 2010 e maio de 2011. Estação Climatológica Principal de Lavras, Departamento de Engenharia, UFLA, Lavras, MG.

O solo na área experimental foi classificado como Latossolo Vermelho distroférrico (EMBRAPA, 2006) e o resultado das análises químicas e físicas (amostra $0,00-0,20 \quad \mathrm{~m}$ profundidade) apresentado na Tabela 1. Quanto ao Mn, salienta-se que o teor verificado, $5,0 \mathrm{mg} \mathrm{dm}^{-3}$, foi classificado como baixo, uma vez que o nível crítico considerado por Ribeiro et al. (1999) é 8,0 $\mathrm{mg} \mathrm{dm}{ }^{-3}$.
O preparo do solo foi constituído de uma aração e uma gradagem. A abertura dos sulcos de semeadura, espaçados em $0,50 \mathrm{~m}$, foi realizada utilizando tração mecanizada. A adubação foi realizada de acordo com as recomendações em Ribeiro et al. (1999). Foram aplicados $400 \mathrm{~kg} \mathrm{ha}^{-1}$ no sulco de semeadura do fertilizante formulado NPK 04-30-10. 
Tabela 1. Resultados das análises químicas e físicas de solo das amostras coletadas $(0,00-0,20 \mathrm{~m})$, na área experimental do Departamento de Agricultura da UFLA em Lavras, MG.

\begin{tabular}{|c|c|c|c|c|}
\hline Parâmetro & Extrator & Unidade & Análise & Interpretação $^{* *}$ \\
\hline $\mathrm{P}$ & Mehlich 1 & $\mathrm{mg} \mathrm{dm}^{-3}$ & 6,2 & Médio \\
\hline $\mathrm{K}$ & Mehlich 1 & $\mathrm{mg} \mathrm{dm} \mathrm{m}^{-3}$ & 83,0 & Bom \\
\hline $\mathrm{Mn}$ & Mehlich 1 & $\mathrm{mg} \mathrm{dm}$ & 5,0 & Baixo \\
\hline $\mathrm{Zn}$ & Mehlich 1 & $\mathrm{mg} \mathrm{dm^{-3 }}$ & 2,9 & Alto \\
\hline $\mathrm{Fe}$ & Mehlich 1 & $\mathrm{mg} \mathrm{dm^{-3 }}$ & 51,5 & Alto \\
\hline $\mathrm{Cu}$ & Mehlich 1 & $\mathrm{mg} \mathrm{dm}$ & 1,9 & Alto \\
\hline $\mathrm{Na}$ & Mehlich 1 & $\mathrm{mg} \mathrm{dm}-3$ & 0,9 & \\
\hline B & Água quente & $\mathrm{mg} \mathrm{dm} \mathrm{dm}^{-3}$ & 0,2 & Baixo \\
\hline S & $\begin{array}{l}\text { Fosfato } \\
\text { monocálcio }\end{array}$ & $\mathrm{mg} \mathrm{dm}{ }^{-3}$ & 80,0 & Muito bom \\
\hline $\mathrm{Ca}$ & $\mathrm{KCl} 1 \mathrm{~mol} \mathrm{~L}^{-1}$ & $\mathrm{cmol}_{\mathrm{c}} \mathrm{dm}^{-3}$ & 2,2 & Médio \\
\hline $\mathrm{Mg}$ & $\mathrm{KCl} 1 \mathrm{~mol} \mathrm{~L}^{-1}$ & $\mathrm{cmol}_{\mathrm{c}} \mathrm{dm}^{-3}$ & 0,8 & Médio \\
\hline Al & $\mathrm{KCl} 1 \mathrm{~mol} \mathrm{~L}^{-1}$ & $\mathrm{cmol}_{\mathrm{c}} \mathrm{dm}^{-3}$ & 0,1 & Muito baixo \\
\hline $\mathrm{H}+\mathrm{Al}$ & SMP & $\mathrm{cmol}_{\mathrm{c}} \mathrm{dm}^{-3}$ & 5,0 & Bom \\
\hline Soma de bases & & $\mathrm{cmol}_{\mathrm{c}} \mathrm{dm}^{-3}$ & 3,2 & Médio \\
\hline CTC efetiva (t) & & $\mathrm{cmol}_{\mathrm{c}} \mathrm{dm}^{-3}$ & 3,3 & Médio \\
\hline CTC pH 7,0 (T) & & $\mathrm{cmol}_{\mathrm{c}} \mathrm{dm}^{-3}$ & 8,3 & Médio \\
\hline Saturação bases (V) & & $\%$ & 38,9 & Baixo \\
\hline Saturação $\mathrm{Al}^{3+}(\mathrm{m})$ & & $\%$ & 3,0 & Muito baixo \\
\hline M.O. & & dag $\mathrm{kg}^{-1}$ & 3,0 & Médio \\
\hline P-rem & & $\mathrm{mg} \mathrm{L}^{-1}$ & 17,6 & \\
\hline $\mathrm{pH} \mathrm{em} \mathrm{H}_{2} \mathrm{O}$ & $\underset{(1 \cdot 2,5)}{\mathrm{KCl} \text { e } \mathrm{CaCl}_{2}}$ & & 5,4 & Acidez média \\
\hline Areia & & dag $\mathrm{kg}^{-1}$ & 27,0 & \\
\hline Silte & & dag $\mathrm{kg}^{-1}$ & 10,0 & \\
\hline Argila & & dag kg-1 & 63,0 & \\
\hline
\end{tabular}

*Análises realizadas no Laboratório do Departamento de Ciência do Solo da Universidade Federal de Lavras (UFLA),

Lavras MG; ${ }^{* *}$ Interpretações de acordo com Ribeiro et al. (1999).

As cultivares de soja utilizadas foram duas convencionais e suas derivadas transgênicas (RR) tolerantes ao herbicida glifosato, conforme Gris et al. (2010), sendo os pares de cultivares: BRS Celeste e BRS Baliza RR, BRSGO Jataí e BRS Silvânia RR, respectivamente.

A semeadura foi realizada no dia 12 de novembro de 2010, as sementes foram tratadas com o fungicida formulado, Carbendazin + Thiram (200 $\mathrm{mL}$ para $100 \mathrm{~kg}$ sementes) e inoculadas com Bradyrhizobium japonicum, utilizando-se inoculante turfoso na proporção de 1.200 .000 bactérias por semente. O desbaste foi realizado 15 dias após emergência das plântulas, mantendo-se 15 plantas por metro, 300.000 plantas por hectare. As parcelas experimentais foram constituídas de 4 linhas de semeadura com 5 metros de comprimento, espaçadas em $0,5 \mathrm{~m}$, sendo que as duas externas constituíram as bordaduras e as duas centrais as linhas úteis, desconsiderando $0,5 \mathrm{~m}$ em cada extremidade, totalizando $10 \mathrm{~m}^{2}$ por parcela, sendo 4 $\mathrm{m}^{2}$ de parcela útil.
Para o controle de plantas invasoras foi utilizado somente o herbicida formulado fluazifopP-butílico + fomesafem, com a dose $0,8 \mathrm{~L} \mathrm{ha}^{-1}$ aplicada aos 25 dias após a emergência da soja, tanto para as cultivares convencionais quanto para as transgênicas RR. Os controles das doenças e pragas foram realizados uniformemente em todas as parcelas de acordo com as necessidades e recomendações para a cultura, utilizando os fungicidas Azoxistrobina + Ciproconazol e Tiofanato-metílico, e os inseticidas Gama-cialotrina e Beta-ciflutrina + Imidacloprido.

Nas aplicações de $\mathrm{Mn}$ via foliar foram utilizadas quatro doses: 0; 200; 400 e $600 \mathrm{~g} \mathrm{Mn} \mathrm{ha}^{-1}$, com aplicação única juntamente com adjuvante vegetal. $\mathrm{Na}$ dose $0 \mathrm{~g} \mathrm{Mn} \mathrm{ha}^{-1}$ foi aplicado água e nas demais a fonte de Mn utilizada foi um produto comercial com garantia de Mn solúvel em água de $137,50 \mathrm{~g} \mathrm{~L}^{-1}$.

A aplicação do Mn foliar foi realizada no estádio de desenvolvimento da planta $\mathrm{R}_{1}$, início do florescimento; ou $\mathrm{R}_{3}$, início da formação da vagem (FEHR et al., 1971). Foi utilizado pulverizador 
costal de pressão constante por $\mathrm{CO}_{2}$, pressão de 2,8 kgf cm${ }^{-2}$ e consumo de calda de $200 \mathrm{~L} \mathrm{ha}^{-1}$, para aplicação do Mn via foliar. No momento da aplicação a parcela foi envolvida com biombo de lona plástica para controle da deriva.

A colheita foi realizada manualmente quando as plantas se encontravam entre $R_{7}$, maturidade fisiológica, e $\mathrm{R}_{8}$, maturação plena (FEHR et al., 1971). As características avaliadas foram: Índice de acamamento (BERNARD et al., 1965: nota 1 todas plantas eretas, 2 algumas plantas inclinadas ou ligeiramente acamadas, 3 todas as plantas moderadamente inclinadas ou $25-50 \%$ acamadas, 4 todas as plantas severamente inclinadas ou $50-80 \%$ acamadas e 5 mais de $80 \%$ acamadas); Número de legumes por planta, avaliado em 10 plantas tomadas aleatoriamente na parcela útil; Peso de mil sementes, seguindo metodologia descrita nas Regras para Análise de Sementes (BRASIL, 2009), e produtividade de sementes, com os valores corrigidos para $13 \%$ de umidade (base úmida) e os resultados convertidos para kilogramas por hectare $\left(\mathrm{kg} \mathrm{ha}^{-1}\right)$.

O delineamento experimental utilizado foi blocos casualizados (DBC) com três repetições. Os tratamentos foram dispostos em esquema fatorial 4 x 4 x 2, envolvendo: quatro cultivares de soja, quatro doses de Mn via foliar e dois estádios de aplicação. Os dados foram submetidos à análise de variância com auxílio do software Sisvar® (FERREIRA, 2011), a 5\% de probabilidade pelo teste F. Os dados de índice de acamamento foram previamente transformados em $\sqrt{x+1}$. Quando pertinente, as médias foram comparadas utilizandose o teste Scott e Knott (1974), a 5\%, ou foram realizadas análises de regressões polinomiais, com a escolha de modelos matemáticos significativos a $5 \%$, com maior valor de coeficiente de determinação.

\section{RESULTADOS E DISCUSSÃO}

Por meio da análise de variância dos resultados das características agronômicas verificouse efeito significativo de cultivar sobre o número de legumes por planta, peso de mil sementes e produtividade, sendo que para o número de legumes por planta e a produtividade também houve efeito de doses. Não houve efeito significativo de estádio de aplicação para qualquer das características agronômicas. As interações significativas foram cultivar*dose para número de legumes por planta e cultivar*dose*estádio para a produtividade.

$O$ índice de acamamento não foi influenciado por qualquer das fontes de variação.
Isto pode estar relacionado a alguns fatores, como os estádios de aplicação do $\mathrm{Mn}$ foliar, $\mathrm{R}_{1}$, início do florescimento, ou $\mathrm{R}_{3}$, início da formação da vagem (FEHR et al., 1971), e ao fato de que todas as cultivares utilizadas apresentam crescimento determinado, ou seja, após $\mathrm{R}_{1}$ o crescimento é nulo. Assim, a altura das plantas não foi afetada $e$, consequentemente, o índice de acamamento também não, devido à tendência da relação entre estes dois fatores.

Para o número de legumes por planta, com as doses em função das cultivares, constatou-se efeito quadrático significativo na cultivar Baliza RR, sendo o valor máximo, 110,51 legumes, obtido com a dose $189,88 \mathrm{~g} \mathrm{Mn} \mathrm{ha}^{-1}$ (Figura 2). Já para cultivar Celeste, o modelo que se ajustou aos dados foi o de terceiro grau, com maior valor alcançado com a dose 120,45 $\mathrm{g} \mathrm{Mn} \mathrm{ha}{ }^{-1}$, atingindo 118,11 legumes por planta. Para a cultivar Jataí foi observado comportamento quadrático do efeito de doses de $\mathrm{Mn}$ foliar, sendo o maior número de legumes por planta, 125,63, proporcionado pela dose 228,78 $\mathrm{g} \mathrm{Mn} \mathrm{ha}^{-1}$. Quanto à Silvânia RR, o comportamento foi linear, com maior valor observado $(98,24)$ com a dose $0 \mathrm{~g} \mathrm{Mn} \mathrm{ha}^{-1}$, sendo verificado efeito negativo da aplicação foliar de $\mathrm{Mn}$ sobre o número de legumes por planta para esta cultivar.

É interessante salientar que as cultivares, com exceção de Silvânia RR cujo comportamento foi peculiar, obtiveram maiores números de legumes por planta com doses próximas a $200 \mathrm{~g} \mathrm{Mn} \mathrm{ha}^{-1} \mathrm{e}$ com as doses mais elevadas os efeitos foram negativos. Ressalta-se que o número de legumes por planta é um dos principais componentes da produtividade. Segundo Ritchie et al. (1997), esta característica é mais responsiva aos tratamentos do que o número de sementes por legume e peso de sementes.

Entre as cultivares em função das doses, na ausência da aplicação do Mn foliar as cultivares não diferiram no número de legumes por planta, porém na utilização das doses 200 e $400 \mathrm{~g} \mathrm{Mn} \mathrm{ha}^{-1}$ os valores obtidos pelas mesmas foram distintos (Tabela 2), indicando assim respostas diferenciais entre elas. Com a dose $200 \mathrm{~g} \mathrm{Mn} \mathrm{ha}^{-1}$ verificou-se que a cultivar Jataí foi superior às demais, seguida de Celeste e Baliza RR que não diferiram entre si, e Silvânia RR com o menor número de legumes por planta. Já com a aplicação de $400 \mathrm{~g} \mathrm{Mn} \mathrm{ha}^{-1}$, Baliza RR e Jataí foram superiores às demais, Celeste e Silvânia RR (Tabela 2). A cultivar Silvânia RR tanto com a utilização de 200 quanto de $400 \mathrm{~g} \mathrm{Mn}$ $\mathrm{ha}^{-1}$ obteve os menores números de legumes por planta, o que influenciou a produtividade em relação 
às demais, por este ser relevante componente produtivo.

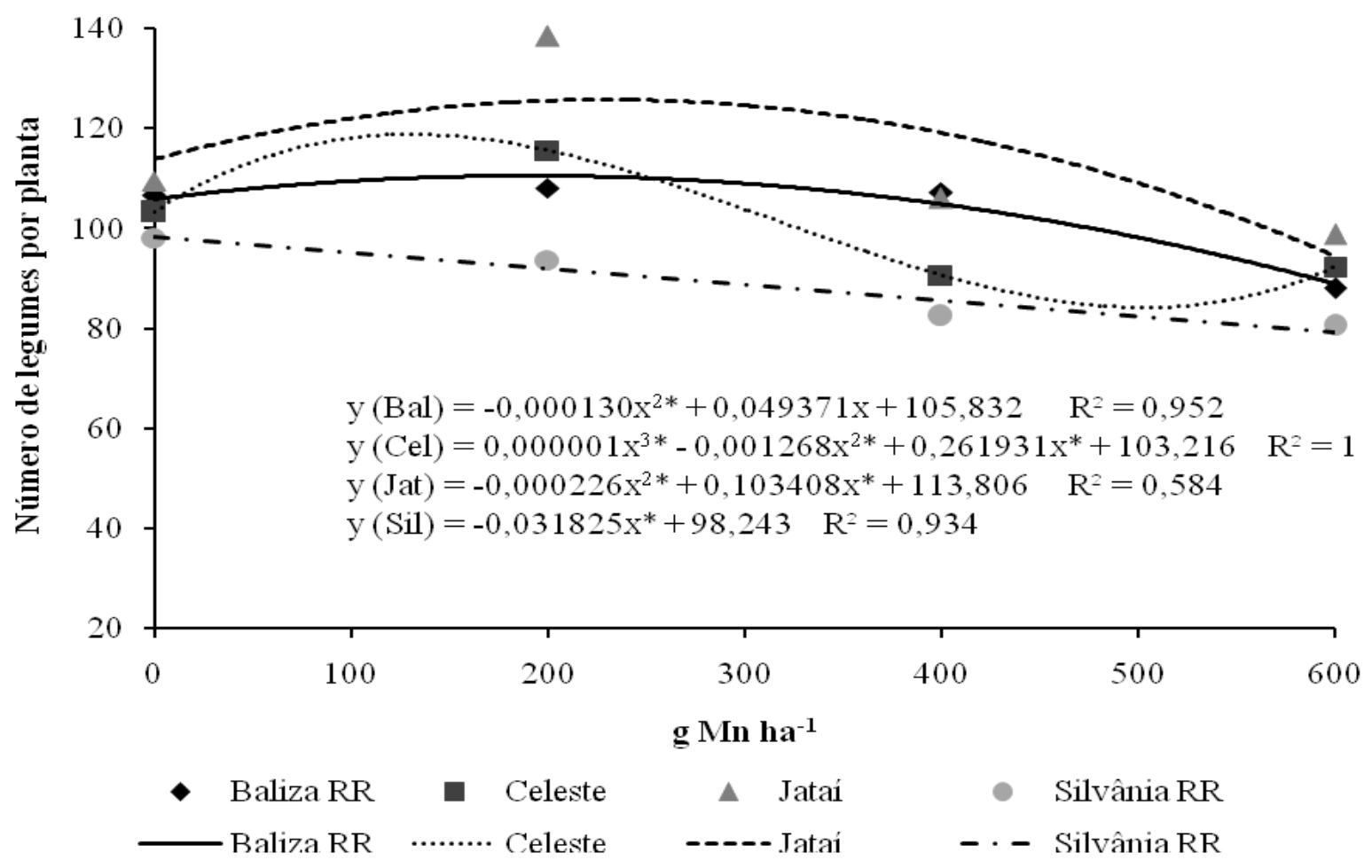

Figura 2. Equação de regressão para número de legumes por planta de soja, em função de doses de Mn foliar aplicadas às plantas de distintas cultivares. *significativo a 5\% de probabilidade pelo teste $\mathrm{F}$.

Tabela 2. Número de legumes por planta de distintas cultivares de soja nas doses de Mn foliar.

\begin{tabular}{|c|c|c|c|c|c|c|c|c|}
\hline \multirow{2}{*}{ Cultivares } & \multicolumn{8}{|c|}{ Doses de Mn foliar* $\left(\mathrm{g} \mathrm{Mn} \mathrm{ha}^{-1}\right)$} \\
\hline & 0 & & 200 & & 400 & & 600 & \\
\hline Baliza RR & 106,65 & $\mathrm{a}$ & 108,06 & $\mathrm{~b}$ & 107,28 & $\mathrm{a}$ & 87,95 & $a$ \\
\hline Celeste & 103,21 & $\mathrm{a}$ & 115,56 & $\mathrm{~b}$ & 90,56 & $\mathrm{~b}$ & 92,30 & $\mathrm{a}$ \\
\hline Jataí & 109,45 & $\mathrm{a}$ & 138,51 & $\mathrm{a}$ & 105,93 & $\mathrm{a}$ & 98,83 & $\mathrm{a}$ \\
\hline Silvânia RR & 98,06 & $\mathrm{a}$ & 93,65 & $\mathrm{c}$ & 82,50 & $\mathrm{~b}$ & 80,56 & $\mathrm{a}$ \\
\hline
\end{tabular}

*Médias seguidas da mesma letra na coluna não diferem entre si, ao nível de 5\% de probabilidade, pelo teste de ScottKnott.

Para o peso de mil sementes, entre a cultivar convencional e sua derivada transgênica RR (Celeste e Baliza RR; Jataí e Silvânia RR) não houve diferença, evidenciando assim a semelhança entre os genótipos derivados. Mas entre os pares de cultivares foi constatado que as médias de Celeste e Baliza RR foram superiores às médias obtidas por Silvânia RR e Jataí (Tabela 3).

Por estes resultados verifica-se a variação desta característica entre genótipos de soja. Camozzato et al. (2009) também constataram diferenças no peso de mil sementes entre cultivares de soja. O que está relacionado ao maior controle genético do peso de sementes em relação ao número de legumes por planta, que é mais responsivo aos tratamentos. Devido à isto, o peso de sementes é dotado de maior resistência às fontes de variações (RITCHIE et al., 1997), sofrendo pouca influência de tratamentos que modifiquem o ambiente, tais como a aplicação de nutrientes. Porém Melarato et al. (2002), trabalhando somente com a cultivar Garimpo e avaliando diferentes fontes e modos de aplicação de Mn em plantas de soja, observaram que a aplicação exerceu influência positiva sobre o peso das sementes produzidas. 
Tabela 3. Peso de mil sementes de distintas cultivares de soja.

\begin{tabular}{crl}
\hline Cultivares & Peso de mil sementes $(\mathrm{g})^{*}$ \\
\hline Celeste & 161,47 & $\mathrm{a}$ \\
Baliza RR & 158,27 & $\mathrm{a}$ \\
Silvânia RR & 154,03 & $\mathrm{~b}$ \\
Jataí & 153,83 & $\mathrm{~b}$ \\
\hline *Médias
\end{tabular}

*Médias seguidas da mesma letra não diferem entre si, ao nível de 5\%, pelo teste de Scott-Knott.

Com base nos resultados de produtividade referentes às doses de $\mathrm{Mn}$ foliar em função de cultivares, verificou-se com a aplicação realizada no estádio $\mathrm{R}_{1}$ regressão significativa apenas para a cultivar Celeste (Figura 3 a), com produtividade máxima $\left(5164,34 \mathrm{~kg} \mathrm{ha}^{-1}\right)$ obtida com 152,05 g Mn $\mathrm{ha}^{-1}$ e a menor média $\left(3459,07 \quad \mathrm{~kg} \mathrm{ha}^{-1}\right)$ proporcionada por 508,98 $\mathrm{g} \mathrm{Mn} \mathrm{ha}^{-1}$. Já com a aplicação realizada em $\mathrm{R}_{3}$, o efeito das doses de $\mathrm{Mn}$ foi significativo para a cultivar Baliza RR, com pontos máximo e mínimo semelhantes ao da cultivar Celeste, sendo que a dose $150,11 \mathrm{~g} \mathrm{Mn} \mathrm{ha}^{-1}$ proporcionou a maior produtividade $(4487,03 \mathrm{~kg} \mathrm{ha}$ $\left.{ }^{1}\right)$ e o menor valor $\left(3168,52 \mathrm{~kg} \mathrm{ha}^{-1}\right)$ obtido com 497,32 $\mathrm{g} \mathrm{Mn} \mathrm{ha}^{-1}$ (Figura 3 b). Indicando desta maneira os efeitos positivos da aplicação foliar com $\mathrm{Mn}$ em doses adequadas, próximas a $150 \mathrm{~g} \mathrm{Mn} \mathrm{ha}^{-1}$, sobre a produtividade destas cultivares em solos com teores de Mn abaixo do nível crítico $(8,0 \mathrm{mg}$ $\mathrm{dm}^{-3}$ ), conforme resultado da análise de solo (Tabela 1). Dados estes que se alinham aos obtidos quanto ao número de legumes por planta (Figura 2), pois nestas cultivares os maiores valores também foram verificados com doses próximas a esta. Resposta semelhante foi obtida por Mann et al. (2002), que em solos com Mn abaixo do nível crítico, verificaram aumento na produtividade, nas duas formas de aplicação do Mn (Solo e foliar), com maior grau de eficiência da aplicação foliar. Mondo et al. (2012) observaram correlação positiva entre o teor de $\mathrm{Mn}$ no solo e a produtividade da soja, ao passo que Basso et al. (2011) constataram que mesmo com aumento no teor foliar de $\mathrm{Mn}$ com a suplementação do micronutriente, não houve incremento no rendimento da soja, porém em solo com teor de Mn acima do suficiente.

Com a aplicação de doses superiores à $150 \mathrm{~g}$ $\mathrm{Mn} \mathrm{ha}{ }^{-1}$ os efeitos foram negativos sobre a produtividade (Figura 3). As menores produtividades para as cultivares Celeste e Baliza $R R$ nos estádios $R_{1}$ e $R_{3}$, respectivamente, foram proporcionadas por doses próximas a $500 \mathrm{~g} \mathrm{Mn} \mathrm{ha}^{-1}$. Isto pode estar relacionado a um excesso do micronutriente nestas doses mais elevadas, visto que foram observados danos visuais de fitotoxidez em todas as cultivares quando foi aplicado $600 \mathrm{~g} \mathrm{Mn} \mathrm{ha}^{-}$ 1 .

A cultivar Baliza RR é derivada transgênica da cultivar Celeste, genótipos semelhantes, em ambas as regressões foram significativas em função das doses de $\mathrm{Mn}$ aplicadas nos estádio $\mathrm{R}_{1}$ ou $\mathrm{R}_{3}$ (Figura 3), para o outro par de cultivares, Jataí e Silvânia RR, isto não foi observado. Sugere-se então que a resposta à adubação com Mn possa estar condicionada ao genótipo e não à modificação genética RR. Corroborando assim com Lavres Júnior et al. (2008) que verificaram indicações de diferenças genotípicas entre cultivares quanto à tolerância ao excesso de Mn em solução. Também Loecker et al. (2010), que relataram que o genótipo influenciou na resposta da planta à aplicação de Mn, que a transgenia $R R$ não proporcionou conclusivamente em maior resposta à aplicação e que nem todos os pares de cultivares (convencional e RR) irão responder da mesma forma.

Vale salientar que o patamar das produtividades verificado no experimento está acima das médias nacionais dos últimos anos, que em 2011/12 foi 2651 e em 2012/13 foi $2968 \mathrm{~kg} \mathrm{ha}^{-1}$ (CONAB, 2013). A média geral do experimento foi $4072 \mathrm{~kg} \mathrm{ha}^{-1}$, mas foram obtidos valores acima de $5000 \mathrm{~kg} \mathrm{ha}^{-1}$.

Em relação às cultivares em função dos estádios de aplicação e doses de Mn foliar, foi verificado que no estádio de aplicação $R_{1}$ as produtividades das cultivares diferiram apenas com a utilização de $200 \mathrm{~g} \mathrm{Mn} \mathrm{ha}{ }^{-1}$, sendo as convencionais superiores às transgênicas RR (Tabela 4). Em $R_{3}$, as produtividades entre as cultivares foram distintas nas dosagens 0 e $400 \mathrm{~g}$ $\mathrm{Mn} \mathrm{ha}^{-1}$. Na ausência da aplicação de Mn observouse que as convencionais foram mais produtivas em relação às suas derivadas $\mathrm{RR}$, o mesmo foi constatado com a aplicação do $\mathrm{Mn}$ foliar na dosagem $400 \mathrm{~g} \mathrm{Mn} \mathrm{ha}^{-1}$ (Tabela 4). 


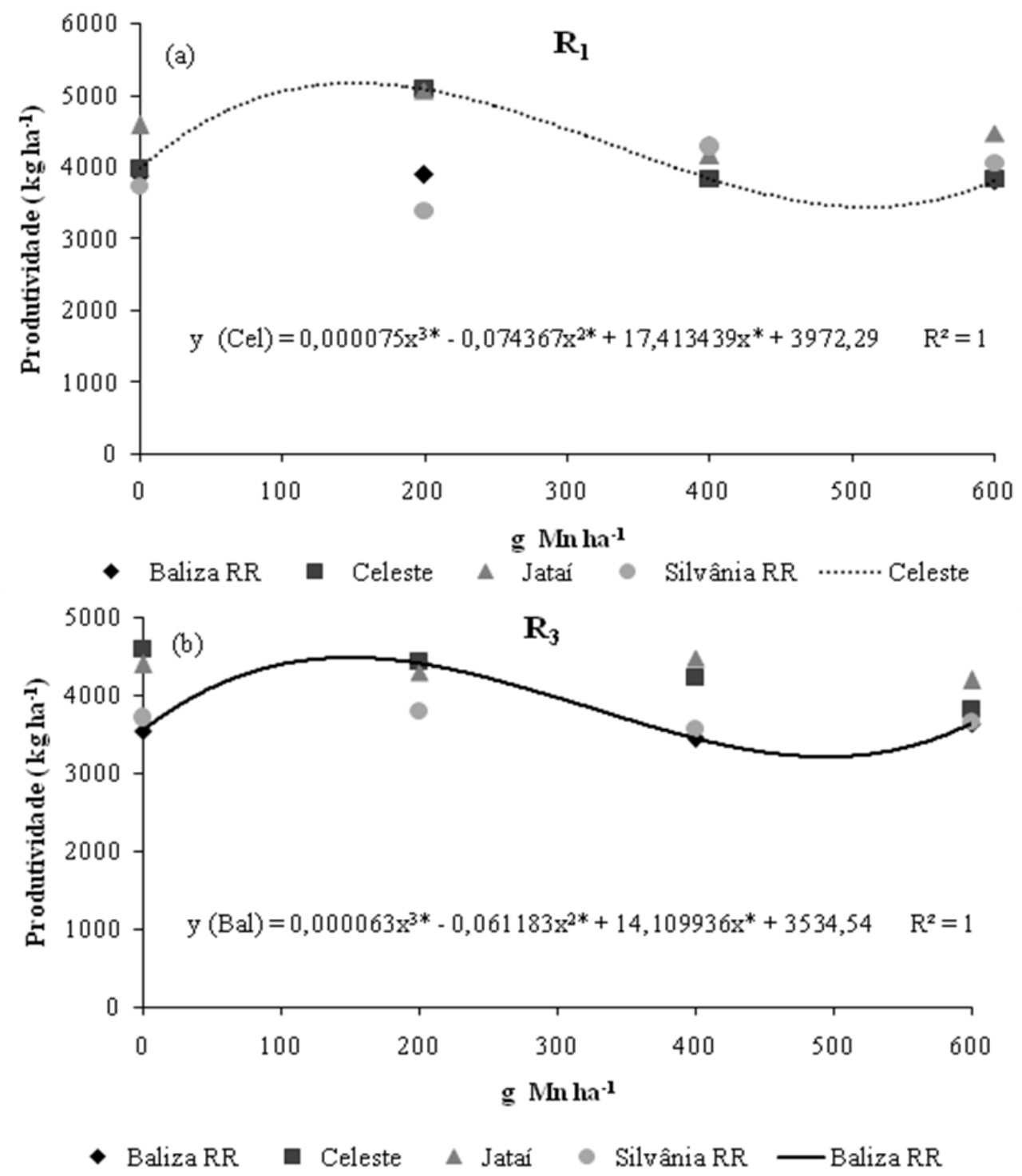

Figura 3. Equação de regressão para produtividade de soja, em função de doses de Mn foliar aplicadas às plantas em diferentes estádios e cultivares. *significativo a $5 \%$ de probabilidade pelo teste $\mathrm{F}$.

De modo geral, com aplicação realizada em $\mathrm{R}_{1}$ ou em $\mathrm{R}_{3}$, quando as cultivares foram distintas, os materiais convencionais foram mais produtivos em relação aos seus derivados transgênicos RR, tanto na ausência quanto na aplicação do Mn foliar (Tabela 4). Corroborando com os resultados obtidos por Loecker et al. (2010), que constataram que a transgenia RR não proporcionou conclusivamente em maior resposta à aplicação de Mn.

Gordon (2007), Bertolin et al. (2010), Silveira e Resende (2010) e Carvalho et al. (2012) também relataram menores produtividades em soja transgênica $\mathrm{RR}$ em relação à convencional. Porém o mesmo não foi observado por Lima et al. (2008), pois verificaram que não há diferença no desempenho produtivo entre as linhagens de soja convencional e de soja transgênica RR.
Convém destacar que apesar das cultivares RR utilizadas neste trabalho serem essencialmente derivadas das respectivas convencionais, por meio de retrocruzamentos, nem sempre se recupera completamente o genótipo do genitor recorrente, em virtude de ciclos menores de recorrência o que pode, por consequência, acarretar em variações entre ambos os materiais (GRIS, 2009). Uma possibilidade para amenizar este efeito, neste caso, seria um número maior de retrocruzamentos antes do lançamento comercial das cultivares, pois com o avanço do melhoramento das cultivares de soja transgênicas RR esta diferença tende a diminuir, igualando convencionais e transgênicas RR.

Quanto aos estádios de aplicação em função das doses de Mn foliar e cultivares, diferenças significativas entre os estádios foram verificadas nas cultivares Baliza RR e Silvânia RR com a aplicação 
de $400 \mathrm{~g} \mathrm{Mn} \mathrm{ha}^{-1}$. Para Baliza RR, no estádio $\mathrm{R}_{1}$ foi observada produtividade de 4279,58 $\mathrm{kg} \mathrm{ha}^{-1}$, já com

aplicação realizada em $\mathrm{R}_{3}$ o valor foi $3436,33 \mathrm{~kg}$ ha' 1 .

Tabela 4. Produtividade $\left(\mathrm{kg} \mathrm{ha}^{-1}\right)$ de cultivares de soja em função dos estádios de aplicação e doses de Mn foliar.

\begin{tabular}{cccccc}
\hline \multirow{2}{*}{ Estádios } & \multirow{2}{*}{ Cultivares } & \multicolumn{4}{c}{ Doses de Mn foliar* $\left(\mathrm{g} \mathrm{Mn} \mathrm{ha}^{-1}\right)$} \\
\cline { 3 - 6 } & Baliza RR & $3864,40 \mathrm{a}$ & $3881,62 \mathrm{~b}$ & $4279,58 \mathrm{a}$ & $3795,26 \mathrm{a}$ \\
\multirow{3}{*}{$\mathrm{R}_{1}$} & Celeste & $3972,29 \mathrm{a}$ & $5079,12 \mathrm{a}$ & $3829,44 \mathrm{a}$ & $3816,07 \mathrm{a}$ \\
& Jataí & $4575,51 \mathrm{a}$ & $5050,15 \mathrm{a}$ & $4151,91 \mathrm{a}$ & $4467,77 \mathrm{a}$ \\
& Silvânia RR & $3719,18 \mathrm{a}$ & $3374,15 \mathrm{~b}$ & $4276,83 \mathrm{a}$ & $4044,67 \mathrm{a}$ \\
\hline \multirow{3}{*}{$\mathrm{R}_{3}$} & Baliza RR & $3534,54 \mathrm{~b}$ & $4415,09 \mathrm{a}$ & $3436,33 \mathrm{~b}$ & $3633,63 \mathrm{a}$ \\
& Celeste & $4591,02 \mathrm{a}$ & $4419,19 \mathrm{a}$ & $4215,31 \mathrm{a}$ & $3813,96 \mathrm{a}$ \\
& Jataí & $4393,08 \mathrm{a}$ & $4293,49 \mathrm{a}$ & $4473,40 \mathrm{a}$ & $4185,44 \mathrm{a}$ \\
& Silvânia RR & $3710,32 \mathrm{~b}$ & $3789,01 \mathrm{a}$ & $3563,60 \mathrm{~b}$ & $3648,18 \mathrm{a}$ \\
\hline
\end{tabular}

*Médias seguidas da mesma letra na coluna não diferem entre si, ao nível de 5\% de probabilidade, pelo teste de ScottKnott.

Em Silvânia RR, o comportamento foi semelhante, com média superior quando o $\mathrm{Mn}$ foi aplicado em $R_{1}, 4276,83 \mathrm{~kg} \mathrm{ha}^{-1}$, em relação à $R_{3}$, $3563,60 \mathrm{~kg} \mathrm{ha}^{-1}$. Na cultivar Jataí, foi constatada diferença entre os estádios com a dose $200 \mathrm{~g} \mathrm{Mn} \mathrm{ha}^{-}$ ${ }^{1}$, sendo a aplicação realizada em $\mathrm{R}_{1} \operatorname{com} 5050,15 \mathrm{~kg}$ ha ${ }^{-1}$ também superior à $\mathrm{R}_{3}, 4293,49 \mathrm{~kg} \mathrm{ha}^{-1}$. Entre as quatro cultivares utilizadas neste trabalho, em três, quando os estádios de aplicação diferiram, seja com a dose $200 \mathrm{ou} 400 \mathrm{~g} \mathrm{Mn} \mathrm{ha}^{-1}$, as produtividades mais elevadas foram verificadas com as aplicações realizadas em $R_{1}$ em relação à $R_{3}$.

\section{CONCLUSÕES}

A transgenia RR em soja não proporciona maior resposta à aplicação de $\mathrm{Mn}$, sendo esta possivelmente condicionada ao genótipo.
Há aumento na produtividade de sementes de soja das cultivares Celeste e Baliza RR em função da aplicação foliar de Mn, em solo com teor de Mn abaixo do nível crítico e produtividades máximas obtidas com $150 \mathrm{~g} \mathrm{Mn} \mathrm{ha}^{-1}$.

A aplicação foliar de $\mathrm{Mn}$ realizada em $\mathrm{R}_{1}$ resulta em maior produtividade de sementes em relação à $R_{3}$.

\section{AGRADECIMENTOS}

Ao Conselho Nacional de Desenvolvimento Científico e Tecnológico (CNPq), pela concessão de bolsas de estudos . À Fundação de Amparo à Pesquisa do Estado de Minas Gerais (FAPEMIG) e ao $\mathrm{CNPq}$ pelo auxílio financeiro, por meio de equipamentos e materiais para a realização do trabalho.

\begin{abstract}
The aim of this study was to evaluate the influence of foliar Mn application in the agronomic characteristics of conventional cultivars soybean and its derived RR (Roundup Ready®, event GTS 40-3-2). The experiment was carried out at the Federal University of Lavras, MG state, using a randomized block design with three replications and a $4 \times 4 \times 2$ factorial structure, with four soybean cultivars, two conventional and its derived RR (BRS

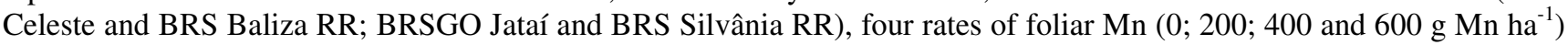
and two stages of application $\left(\mathrm{R}_{1}\right.$ or $\left.\mathrm{R}_{3}\right)$. It was evaluated the agronomic traits: lodging index, number of pods per plant, thousand seed weight and seeds yield. The response to the application of Mn might be conditioned to the genotype rather than to the RR genetic modification, with increase in seed yield of Baliza RR and Celeste with of foliar Mn application, in soil with Mn content below a critical level and maximum yields obtained with $150 \mathrm{~g} \mathrm{Mn} \mathrm{ha}{ }^{-1}$. The foliar application of Mn in $R_{1}$ results in a higher seed yield in relation to $R_{3}$.
\end{abstract}

KEYWORDS: Glycine max. Mineral nutrition. Roundup Ready Soybean.

\title{
REFERÊNCIAS
}

ANDRADE, G. J. M.; ROSOLEM, C. A. Absorção de manganês em soja RR sob efeito do glifosate. Revista Brasileira de Ciência do Solo, Viçosa, MG, v. 35, n. 3, p. 961-968, 2011. 
BASSO, C. J.; SANTI, A. L.; LAMEGO, F. P.; GIROTTO, E. Aplicação foliar de manganês em soja transgênica tolerante ao glyphosate. Ciência Rural, Santa Maria, v. 41, n. 10, p. 1726-1731, 2011. http://dx.doi.org/10.1590/S0103-84782011001000008

BERNARD, R. L.; CHAMBERLAIN, D. W.; LAWRECE, R. D. (Ed.). Results of the cooperative uniform soybean tests. Washington: USDA, 1965. $134 \mathrm{p}$.

BERTOLIN, D. C.; SÁ, M. E.; ARF, O.; FURLANI JUNIOR, E.; COLOMBO, A. S.; CARVALHO, F. L. B. M. Aumento da produtividade de soja com a aplicação de bioestimulantes. Bragantia, Campinas, v. 69, n. 2, p. 339-347, 2010. http://dx.doi.org/10.1590/S0006-87052010000200011

BOTT, S.; TESFAMARIAM, T.; CANDAN, H.; CAKMAK, I.; RÖMHELD, V.; NEUMANN, G. Glyphosateinduced impairment of plant growth and micronutrient status in glyphosate-resistant soybean (Glycine max L.). Plant Soil, Dordrecht, v. 312, n. 1/2, p. 185-194, 2008. http://dx.doi.org/10.1007/s11104-008-9760-8

BRASIL. Ministério da Agricultura e da Reforma Agrária. Departamento Nacional de Meteorologia. Normais climatológicas: 1961-1990. Brasília, 1992. 84 p.

BRASIL. Ministério da Agricultura, Pecuária e Abastecimento. Regras para análise de sementes. Brasília, 2009. 395 p.

CAMOZZATO, V. A.; PESKE, S. T.; POSSENTI, J. C.; MENDES, A. S. Desempenho de cultivares de soja em função do tamanho das sementes. Revista Brasileira de Sementes, Londrina, v. 31, n. 1, p. 288-292, 2009.

CARVALHO, E. R.; REZENDE, P. M.; PASSOS, A. M. A.; OLIVEIRA, J. A. Diagnose foliar e produtividade da soja, em razão de doses e tecnologias de manufatura de fertilizantes formulados NPK. Revista Brasileira de Ciências Agrárias, Recife, v. 7, n. 3, p. 402-408, 2012. http://dx.doi.org/10.5039/agraria.v7i3a1308

CONAB - COMPANHIA NACIONAL DE ABASTECIMENTO. Acompanhamento da Safra Brasileira de Grãos 2012/13 - Sexto Levantamento - Março/2013. Disponível em:

$<$ http://www.conab.gov.br/conteudos.php?a=1253\&t=2>. Acesso em: 25 mar. 2013.

CORREIA, N. M.; DURIGAN, J. C. Glyphosate e adubação foliar com manganês na cultura da soja transgênica. Planta Daninha, Viçosa, MG, v. 27, n. 4, p. 721-727, 2009.

DANTAS, A. A. A.; CARVALHO, L. G.; FERREIRA, E. Classificação e tendências climáticas em Lavras, MG. Ciência e Agrotecnologia, Lavras, v. 31, n. 6, p. 1862-1866, 2007.

EMBRAPA - EMPRESA BRASILEIRA DE PESQUISA AGROPECUÁRIA . Sistema brasileiro de classificação de solos. 2.ed. Rio de Janeiro: Embrapa Solos, 2006. 306 p.

FEHR, W. R.; CAVINESS, C. E.; BURMOOD, D. T.; PENNINGTON, J. S. Stage of development descriptions for soybeans, Glycine max (L.) Merril. Crop Science, Madison, v. 11, n. 6, p. 929-931, 1971. http://dx.doi.org/10.2135/cropsci1971.0011183X001100060051x

FERREIRA, D. F. Sisvar: a computer statistical analysis system. Ciência e Agrotecnologia, Lavras, v. 35, n. 6, p. 1039-1042, 2011.

GORDON, B. Manganese nutrition of glyphosate-resistant and conventional soybeans. Better Crops, Georgia, v. 91, n. 4, p. 12-13, 2007.

GRIS, C. F. Qualidade fisiológica de sementes de soja convencional e RR associada ao conteúdo de lignina. 2009. 134 p. Tese (Doutorado em Fitotecnia) - Universidade Federal de Lavras, Lavras, 2009.

GRIS, C. F.; VON PINHO, E. V. R.; ANDRADE, T.; BALDONI, A.; CARVALHO, M. L. M. Qualidade fisiológica e teor de lignina no tegumento de sementes de soja convencional e transgênica RR submetidas a diferentes épocas de colheita. Ciência e Agrotecnologia, Lavras, v. 34, n. 2, p. 374-381, 2010. 
HUBER, D. M.; LEUCK; J. D.; SMITH, W. C.; CHRISTMAS, E. P. Induced manganese deficiency in GM soybeans. In: Induced manganese deficiency in GM soybeans. NORTH CENTRAL EXTENSION-INDUSTRY SOIL FERTILITY CONFERENCE, 34., 2004, Des Moines. Proeedings... Brookings: IPNI, 2004. p. 80-83.

LAVRES JUNIOR, J.; MORAES, M. F.; CABRAL, C. P.; MALAVOLTA, E. Influência genotípica na absorção e na toxidez de manganês em soja. Revista Brasileira de Ciência do Solo, Viçosa, MG, v. 32, n. 1, p. 173-181, 2008.

LIMA, W. F.; PÍPOLO, A. E.; MOREIRA, J. U. V.; CARVALHO, C. G. P.; PRETE, C. E. C.; ARIAS, C. A. A.; OLIVEIRA, M. F.; SOUZA, G. E.; TOLEDO, J. F. F. Interação genótipo-ambiente de soja convencional e transgênica resistente a glifosato, no Estado do Paraná. Pesquisa Agropecuária Brasileira, Brasília, v. 43, n. 6, p. 729-736, 2008. http://dx.doi.org/10.1590/S0100-204X2008000600009

LOECKER, J. L.; NELSON, N. O.; GORDON, W. B.; MADDUX, L. D.; JANSSEN, K. A.; SCHAPAUGH, W. T. Manganese Response in Conventional and Glyphosate Resistant Soybean. Agronomy Journal, Madison, v. 102, n. 2, p. 606-611, 2010. http://dx.doi.org/10.2134/agronj2009.0337

MANN, E. N.; REZENDE, P. M.; MANN, R. S.; CARVALHO, J. G.; VON PINHO, E. V. R. Efeito da aplicação de manganês no rendimento e na qualidade de sementes de soja. Pesquisa Agropecuária Brasileira, Brasília, v. 37, n. 12, p. 1757-1764, 2002. http://dx.doi.org/10.1590/S0100-204X2002001200012

MELARATO, M.; PANOBIANCO, M.; VITTI, G. C.; VIEIRA, R. D. Manganês e potencial fisiológico de sementes de soja. Ciência Rural, Santa Maria, v. 32, n. 6, p. 1069-1071, 2002.

http://dx.doi.org/10.1590/S0103-84782002000600025

MONDO, V. H. V.; GOMES JUNIOR, F. G.; PINTO, T. L. F.; MARCHI, J. L.; MOTOMIYA, A. V. A.; MOLIN, J. P.; CICERO, S. M. Spatial variability of soil fertility and its relationship with seed physiological potential in a soybean production area. Revista Brasileira de Sementes, Londrina, v. 34, n. 2, p. 193-201, 2012.

RIBEIRO, A. C.; GUIMARÃES, P. T. G.; ALVAREZ, V. V. H. (Ed.). Recomendação para o uso de corretivos e fertilizantes em Minas Gerais: $5^{\text {a }}$ aproximação. Viçosa, MG: Comissão de Fertilidade do Solo do Estado de Minas Gerais, 1999. 359 p.

RITCHIE, S. W.; HANWAY, J. J.; THOMPSON, H. E.; BENSON, G. O. How a soybean plant develops. Ames: Iowa State University of Science, 1997. 20 p. (Special Report, 53).

ROSOLEM, C. A.; ANDRADE, G. J. M.; LISBOA, I. P.; ZOCA, S. M. Manganese uptake and redistribution in soybeans as affected by glifosate. Revista Brasileira de Ciência do Solo, Viçosa, MG, v. 34, n. 6, p. 19151922, 2010.

SCOTT, A. J.; KNOTT, M. A cluster analysis method for grouping means in the analysis of variance. Biometrics, Washington, v. 30, p. 507-512, 1974. http://dx.doi.org/10.2307/2529204

SILVEIRA, J. V. F.; RESENDE, L. M. Estratégias de mercado no agronegócio paranaense: soja convencional vs. Transgênica. Produção, São Paulo, v. 20, n. 1, p. 54-65, 2010.

STEFANELLO, F. F.; MARCHETTI, M. E.; SILVA, E. F.; STEFANELLO, J.; DORETO, R. B. S.; NOVELINO, J. O. Efeito de glyphosate e manganês na nutrição e produtividade da soja transgênica. Semina: Ciências Agrárias, Londrina, v. 32, n. 3, p. 1007-1014, 2011.

ZOBIOLE, L. H. S.; OLIVEIRA JÚNIOR, R. S.; HUBER, D. M.; CONSTANTIN, J.; CASTRO, C.; OLIVEIRA, F. A.; OLIVEIRA JÚNIOR, A. Glyphosate reduces shoot concentrations of mineral nutrients in glyphosate -resistant soybeans. Plant Soil, Dordrecht, v. 328, n. 1/2, p. 57-69, 2010.

http://dx.doi.org/10.1007/s11104-009-0081-3 